\title{
Water Level Variation Equipment in Geotechnical Centrifuge
}

\author{
Yue Zhao 1, 2,a * Jiandong $\mathrm{Li}^{1,2, \mathrm{~b}}$ and Yi Meng ${ }^{1,2, \mathrm{c}}$ \\ 1 Tianjin Research Institute for Water Transport Engineering, M.O.T, Tianjin 300456, China \\ ${ }^{2}$ National Engineering Laboratory for Port Hydraulic Construction Technology, Tianjin 300456, \\ China \\ atkyjacob@163.com, bjiandongli09@163.com, ‘my.870120@163.com
}

\begin{abstract}
Keywords: water level variation equipment, geotechnical centrifuge, slopes failure
Abstract. In order to study slopes failure process with water level changing in the geotechnical centrifuge, to detail analyze deformation or collapse of the slopes, in this paper, different characteristics of some water level variation equipments in geotechnical centrifuge have been studied, on the base of these different solutions, a new type of water level variation equipment has been proposed, this equipment can make water level changing accurately and smoothly in the huge centrifugal field.
\end{abstract}

\section{Introduction}

River bank slopes, embankment slopes and reservoir bank slopes are different from dry land slopes, which are most likely to slide or collapse under the action of water level repeat changes. This phenomenon has presented new challenges on slope stability problem. Aiming at solving problems under water level changing condition, a lot of fruitful work have been carried out by scholars, such as mechanical analysis method, numerical modeling method, field monitoring method, model test as well as field experiments[1]. In all these research methods, Geotechnical centrifuge model tests have been proved to be more particularly valuable in revealing me deformation and collapse mechanisms, and are wildly applied in geotechnical engineering [2-5]. Especially in the study on soil slope deformations and failures, because it can reproduce the weight stress field and the deformation process in the model by building a reduced scale version of the prototype according to the scaling laws in geotechnical centrifuge. It is an ideal method to research slope stability problems under water level changing condition. Working performance of water level variation equipment will be affected by high gravity in the direction of centrifugal acceleration, so study the working performance of the water level variation equipment in high centrifugal field has important significance.

In order to solve slope failure problems under water level changing condition with geotechnical centrifuge test method, a new type of water level variation equipment working in geotechnical centrifuge is in urgent need.

\section{Scaling Law of Water Level Change}

The experimental model is placed in the centrifuge basket during geotechnical centrifuge tests, the centrifugal force loaded on the model can be regarded as $\mathrm{N}$ times of gravity. If the soil in the experimental model is same as in the prototype, the stress at the depth $\mathrm{hm}$ in the model is same as the depth hp in the prototype when the centrifuge spins to $\mathrm{Ng}$ ( $\mathrm{N}$ times of the gravity), then we can get the following equation, $\mathrm{hp}=\mathrm{Nhm}$, it is the basic similarity law in the geotechnical centrifuge test, the scaling factors in geotechnical centrifugal test is shown in Table 1. 
Table 1. Scaling Factors of Model to Prototype.

\begin{tabular}{cc}
\hline Physical variable & Scaling factors (model/prototype) \\
\hline Acceleration $a$ & $\mathrm{~N}$ \\
Linear dimension $L$ & $1 / \mathrm{N}$ \\
Area $A$ & $1 / \mathrm{N}^{2}$ \\
Volume $V$ & $1 / \mathrm{N}^{3}$ \\
time (consolidation/seepage) $t$ & $1 / \mathrm{N}^{2}$ \\
Seepage speed $v$ & $\mathrm{~N}$ \\
Permeability $k$ & $\mathrm{~N}$ \\
Settlements $s$ & $\mathrm{~N}$ \\
Stress $\sigma$ & 1 \\
Strain $\varepsilon$ & 1 \\
Force $F$ & $1 / \mathrm{N}^{2}$ \\
Density $\rho$ & 1 \\
Mass $m$ & $1 / \mathrm{N}^{3}$ \\
Bending rigidity $E I$ & $1 / \mathrm{N}^{4}$ \\
\hline
\end{tabular}

Soil slope deformation and failure process under the water level changing condition is related to the seepage in soil, so the distance of water level change in the experimental model is $1 / \mathrm{N}$ times comparing with the prototype, and the time similarity of the water level changing is same as seepage process, $1 / \mathrm{N} 2$, according to the similarity law of the geotechnical centrifuge test. Then the velocity similarity can be got by formula derivation, velocity of the water level changing in the experimental model is $\mathrm{N}$ times greater than in prototype, $\mathrm{Vm}=\mathrm{NVp}$.

As we can know from the scaling laws in the geotechnical centrifuge test, the water level changing process must be more precise and faster during the tests.

\section{Comparison of Water Level Change Schemes}

To research slope failure under water level changing condition with geotechnical centrifuge test, a few special equipments have been developed, the solving schemes are as follow:

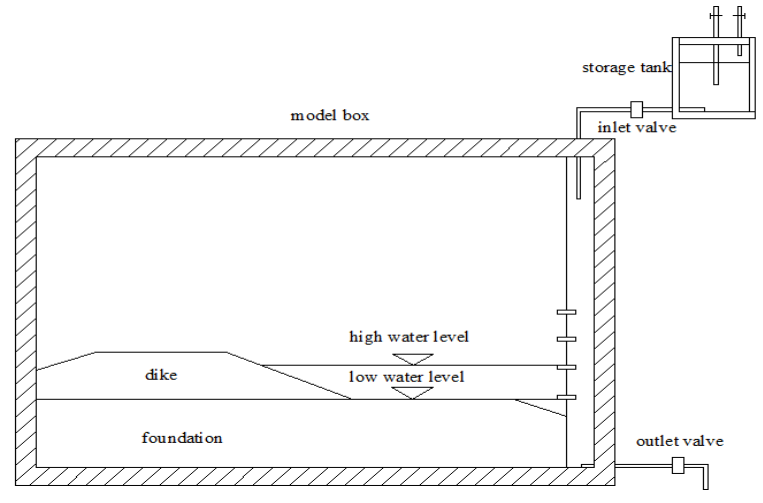

Figure 1. Water level changing equipment.

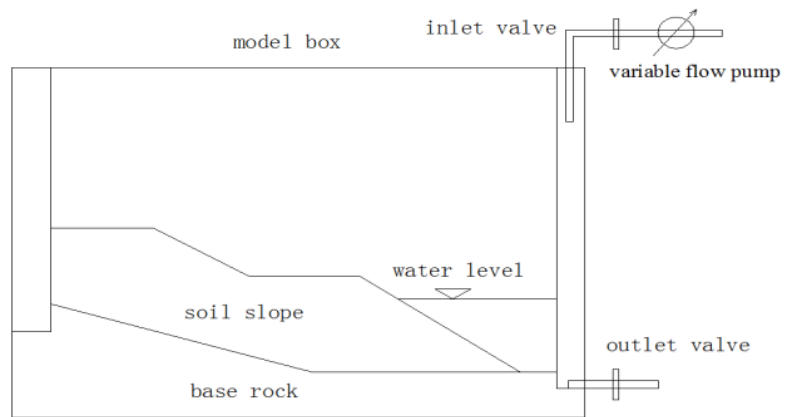

Figure 2. Water level change equipment.

Gao Changsheng, Chen Shengshui et al. [6] have studied the methods to get the safety factors by ruinous geotechnical centrifuge model test method. As Shown in Figure 1, the main equipment is composed of a storage tank, an inlet solenoid valve, a outlet solenoid valve, pipelines and water level 
sensors. First, spin the centrifuge to the set centrifugal acceleration, then open the inlet solenoid valve and begin to fill water into the model box, shut off the inlet solenoid valve when the water level reaches the preset level. Second, maintain the water level for a period of time in accordance with the test requirements, and then open the outlet solenoid valve to let water out, the water level begin to drop. Although this equipment can simulate water level changing process in the geotechnical centrifuge, water in storage tank flows into the model box at a very high speed because of the high centrifugal field. It is difficult to control speed of the water level changes, and also it is not easy to realize the repeated changing of the water level during the tests.

In order to evaluate the slope stability influenced by water level changing process, Li Shaojun, Knappett J A and Feng Xiating [7] carried out a geotechnical centrifugal test. A Three Gorges soil slope model has been built in the geotechnical centrifuge to simulate the whole process of the slope instability caused by water level changing, a series of important test data are obtained through the technique of digital photography, image processing and transducers measurement. As shown in Figure 2, the water level change equipment is composed of pipelines, a variable flow pump, an inlet solenoid valve, an outlet solenoid valve, a water supply box, water level sensors and pore-water pressure transducers. The major advantage of this equipment is, water rising process can be controlled more accurately by adjusting the inlet solenoid valve and the variable flow pump. During water level descending period, water level in the model box can be controlled using water level sensors and the outlet solenoid valve. However, water level drawdown velocity cannot be controlled during the tests.

In order to simulate the groundwater level changing in geotechnical centrifuge test, a groundwater control system has been designed by Zhang Min and NG Charles W W [8], the equipment is shown in Figure 3. This system is consisted of the water supply part and the control part. A desirable groundwater table can be obtained via a solenoid valve and the water pore pressure transducers. The satisfactory test results were obtained in this test using the groundwater control system. Water level changing in the model box can be controlled by this method, but it is not aimed at solving slope failure problems.

Sun Zhenyue, Zhang Ga et al [9] carried out the geotechnical centrifuge model tests to investigate the ground settlement caused by groundwater pumping. As shown in Figure 4, a drainage system was developed to simulate water pumping process using in the geotechnical centrifuge tests. The histories of pore pressure and deformation of the soils were measured during the centrifuge test. Water in the model can be discharged from drain hole under the effect of centrifugal force. Water discharging volume and time can be controlled by exhaust air or filling air into the air bag. Water level can only drops down using this equipment, so it cannot apply to research slope problems under action of repeated water level change.

mode1 box

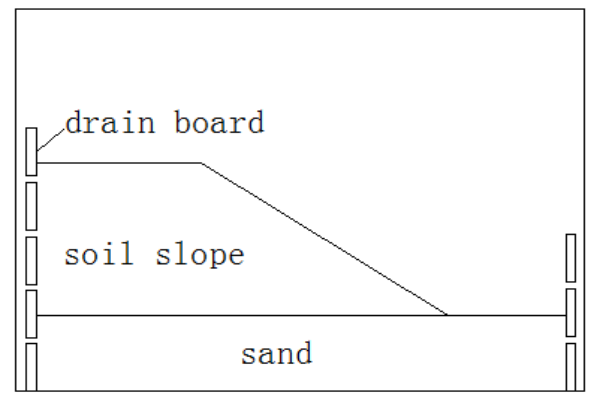

Figure 3. Groundwater control system.

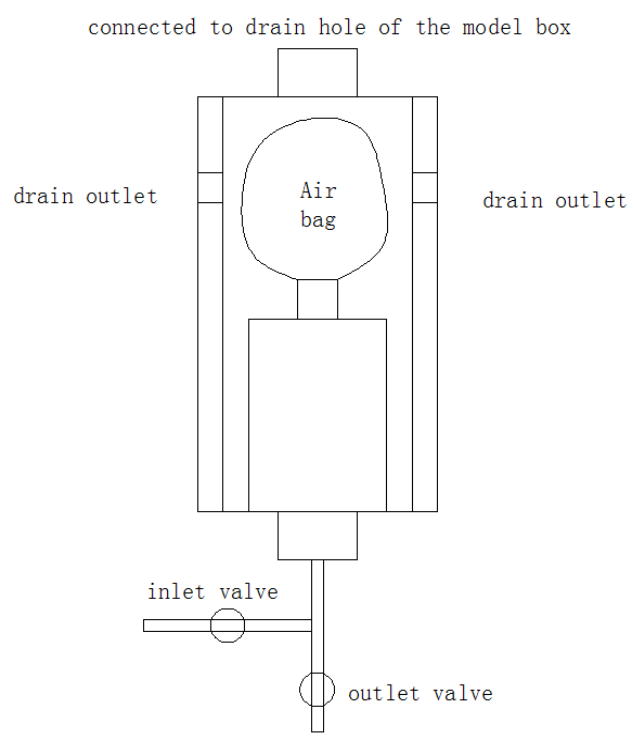

Figure 4. Drainage system for ground settlement. 
From the above we can know, it is difficult to make water level changing accurately and smoothly in the geotechnical centrifuge with the above existing methods. In order to research slope failure problems under the effects of water level repeated changing, it is necessary to develop a new type of water level variation equipment.

\section{Water Level Variation Equipment}

The water level variation equipment works in the high centrifugal field produced by geotechnical centrifuge, it needs to overcome the effect of huge centrifugal force. In order to obtain good test results, water level must be changed smoothly and can be change repeatedly while the geotechnical centrifuge spinning. Through the comparison of the above solving plans, considering characteristics of water level repeated changing, water level is regulated using pressure control method in this new water level variation equipment.

The new type of water level variation equipment has been patented, as shown in Figure 5, Figure 6, Figure 7 and Figure 8, the main structural of the equipment is as follows. The model box is placed in the centrifuge basket, a number of columns are mounted on the bottom board of the model box to support a plate, the slope model will be built on the plate, some uniformly distributed water holes are on the bottom of one side board which is away from the slope toe. There is a filter installed on every water hole. An enclosed water tank is standing side by side with the model box. An equal number of water holes on the water box are connected to the model box water holes with pipe lines. There is a drain valve on the bottom of the water tank, an air tube and a release valve are on the top of the water tank. The specific operation method of the water level variation equipment is as follows. Change the water level by controlling the compressed air pressure in the enclosed water tank. Fill the compressed air into the water tank through the air tube, water in the enclosed tank will be forced into the model, water flows back into the water tank while the compressed air pressure is lower than the water pressure in the model box, water level remains unchanged when compressed air in the enclosed water tank and water in model box are equal.

The advantages of this water level variation equipment are as follow. Water level in the model box changes smoothly with the air pressure, the technical scheme of this equipment can overcome the complex turbulent flow problems when water flows between the enclosed water tank and the model box. The centrifugal force has little influence on the compressed air due to small air density, the flow rate of compressed air can be very high even in the high centrifugal field, so water level can change at high speed. During the test, water is flowing between the model box and the enclosed water tank, water volume is kept constant, water level can be lift and fall repeatedly while the geotechnical centrifuge is spinning. There are filters on each water hole to keep water clean, so local damage of the slope in the model will not affect the operation of the water level variation equipment.

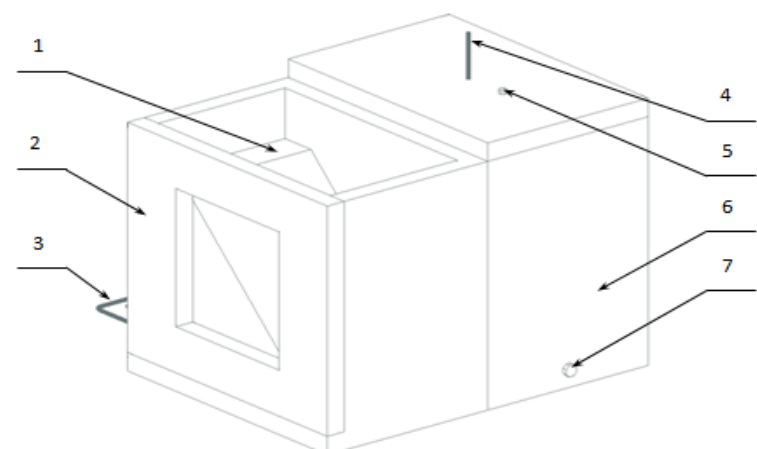

Figure 5. Water level variation equipment.

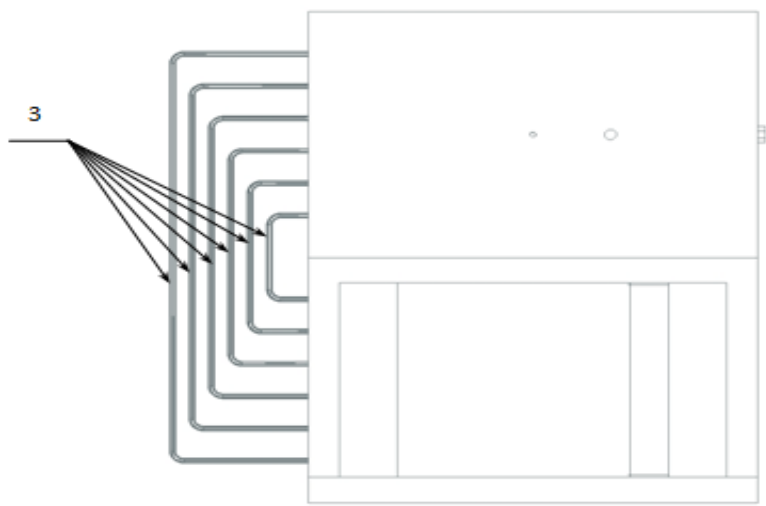

Figure 6. Top view of the equipment. 


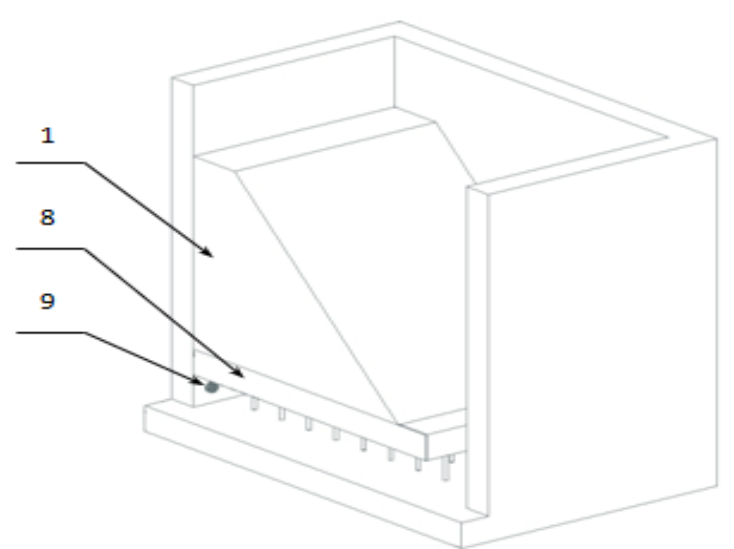

Figure 7. Internal schematic of the equipment.

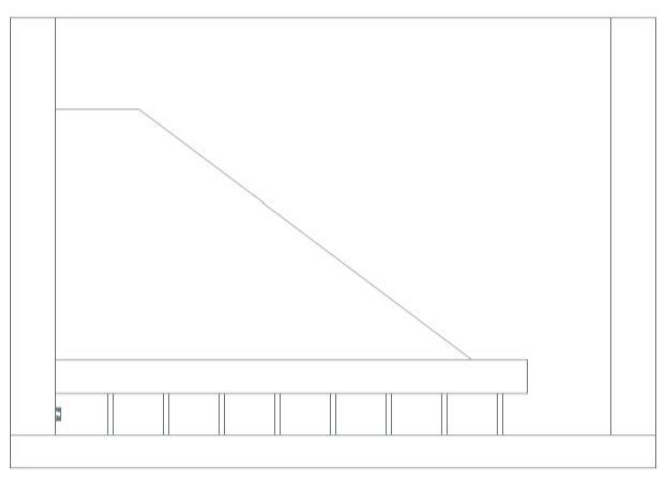

Figure 8. Left view of the internal schematic.

In the above Figures, 1-slope model, 2-model box, 3-pipelines, 4- air tube, 5- release valve, 6enclosed water tank, 7- drain valve, 8-plate, 9- filter.

\section{Conclusion}

The new type water level variation equipment in this paper, water level is regulated by controlling the compressed air pressure in the enclosed water tank, water level can be lifted and fell down repeatedly while the geotechnical centrifuge is spinning. This equipment can overcome the complex turbulent flow problems when water flows between the enclosed water tank and the model box, it works well in the high centrifugal field produced by geotechnical centrifuge.

\section{References}

[1] Wang Sijing, Huang Dingcheng. Centurial achievements of engineering geology in China [M]. Beijing: Geological Publishing House, 2004: 1-21. (in Chinese)

[2] Bao Chenggang. State and prospect of centrifugal model test in China [J]. Chinese Journal of Geotechnical Engineering, 1991, 13(6): 92-97. (in Chinese)

[3] You Xinhua, Li Xiao. Current status and prospect of application of centrifugal model test to slope engineering [J], Journal of Engineering Geology, 2000, 8(4): 442-445. (In Chinese)

[4] Huang Zhiquan, Wang Sijing. A study of application of centrifugal model testing in China [J], Chinese Journal of Rock Mechanics and Engineering, 1998, 17(2): 199-203. (In Chinese)

[5] Hu Liming, Loirene M C, Zhang Jianhong, et al. Application of centrifuge modelling technique to geo-environmental engineering [J]. Soil and Environmental Science, 2001, 10(4): 327-330. (In Chinese)

[6] Gao Changsheng, Chen Shengshui et al. Centrifugal model test on slope stability of level project [J]. Chinese Journal of Rock Mechanics and Engineering, 2005, 24(23): 4308-4312. (In Chinese)

[7] Li Shaojun, Knappett J A and Feng Xiating. Centrifugal test on slope instability influenced by rise and fall of reservoir water level [J]. Chinese Journal of Rock Mechanics and Engineering, 2008, 27(8): 1586-1593. (In Chinese)

[8] Zhang Min, NG Charles W W. Groundwater control technique in centrifuge tests [J]. Rock and Soil Mechanics, 2010, 31(2): 355-360. (In Chinese)

[9] Sun Zhenyue, Zhang Ga et al. Centrifuge modelling of ground settlement due to groundwater pumping [J]. CHINA CIVIL ENGINEERING JOURNAL, 2008, 41(4): 67-72. (In Chinese) 